\title{
Saving Begins at Home
}

Ultimately, Latin America's low saving rate can be traced back to individual households throughout the region. Why do they-or do they not-save and how? Answering this question is not an easy task. Understanding how people make their saving decisions demands more than an analysis of how the financial system interacts with its individual savers. It requires a closer look into their communities, their homes-and even their minds.

Saving rates in Latin America and the Caribbean are low compared to other regions (Chapter 2). This chapter zooms in on households to find out why people in the region save so little. It evaluates some of the difficulties that households in the region encounter when they try to save, analyzes the effects of these constraints on their financial portfolios, and identifies strategies that may boost household saving rates.

\section{Constraints to Saving}

Several factors can limit households' saving choices. These constraints can affect either the choice to save formally or more generally, saving behavior.'

\section{Too Hard to Save Formally?}

Nothing in life is free, and saving is no exception. When saving is done through a formal financial institution, the monetary costs of managing a saving account make households think twice about opening or using the account, especially when yields do not compensate for these costs. ${ }^{2}$ Given high transaction costs-ranging from opening fees and minimum balance requirements to transaction and withdrawal fees-many households find that it simply costs too much to use a financial institution. 
In other parts of the world, reducing these monetary costs has proven to be effective in encouraging people to open formal saving products. Subsidies that cut the cost of opening and maintaining a bank account yielded take-up rates (i.e., new accounts opened among those that were offered) as high as 82 percent in Nepal (Prina, 2015) and between 47 percent and 62 percent in Kenya (Dupas et al., 2016; Dupas and Robinson, 2013a). In the Philippines, programs that reduce transaction costs also have had positive, albeit more modest, effects in inspiring people to open formal saving accounts (Ashraf, Karlan, and Yin, 2006). However, better financial conditions such as higher interest rates have had only a limited effect on households' usage of formal saving accounts in Chile (Kast, Meier, and Pomeranz, 2012) and the Philippines (Karlan and Zinman, 2014). Even when financial institutions offer large, subsidized marginal yields, people often respond little to these incentives.

In recent years, various Latin American and Caribbean countries have made major regulatory advances to promote basic or simplified saving accounts with low transaction costs. Other interesting cost-cutting innovations include the expansion of agent banking and the use of virtual technologies to extend the reach of formal financial institutions to underserved geographical areas. Despite their tremendous potential and their rapidly growing popularity in several countries, regulatory challenges and other barriers still limit their expansion. On the one hand, regulatory frameworks that authorize the use of agent banking in the region have developed only slowly. On the other hand, several issues arise when trying to regulate mobile wallets, phone banking and other virtual technologies. In several Latin American and Caribbean countries, regulation deters the use of these technologies since only authorized financial institutions are allowed to collect deposits from the public. ${ }^{3}$

Credible and well-designed regulation may also help address another formidable barrier to formal saving: lack of trust. Latin America's long record of financial crises and bank runs is etched in the memories of potential savers. Following "lack of money," "lack of trust in banks" is the number two reason given for not having a formal account, as reported in the Global Financial Inclusion (Global FINDEX) database (DemirgüçKunt and Klapper, 2012). Globally, Latin America and the Caribbean ranks highest among regions in terms of this barrier, well above East Asia and the Pacific (see Figure 9.1). Unfortunately, there is no causal evidence linking the lack of trust in banks with the level of formal savings in an economy. Since trust takes years to build and draws on personal and 
Figure 9.1 Lack of Trust as a Barrier to Open a Formal Bank Account

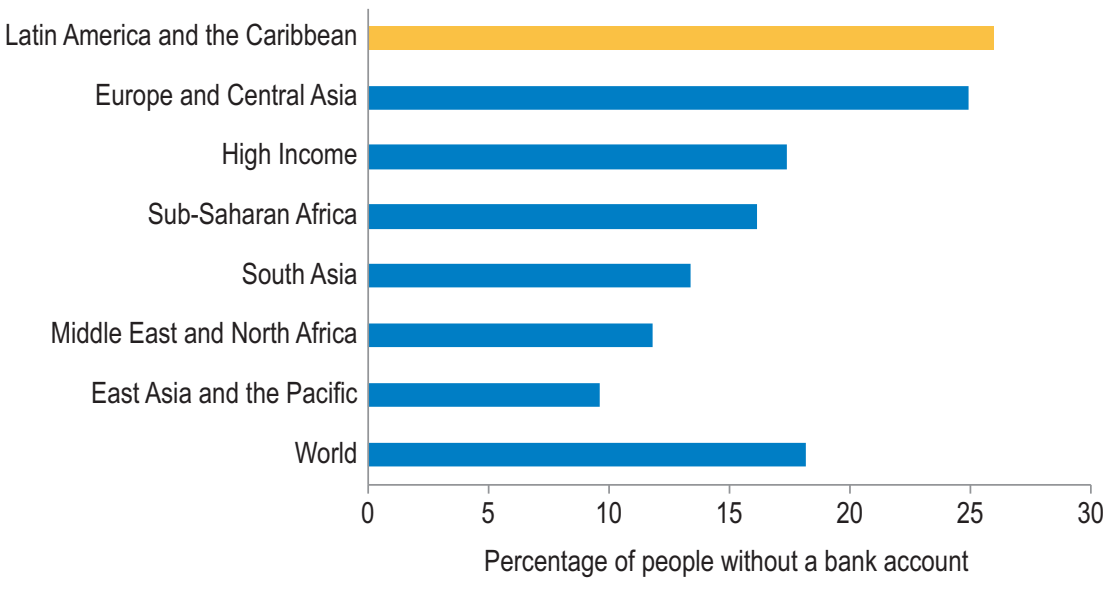

Source: Authors' elaboration based on Global FINDEX dataset (Demirgüç-Kunt and Klapper, 2012).

social history as well as other contextual factors, it is hard to isolate its effect on formal saving rates.

The region's tortuous history of financial crises may not be the only reason behind people's distrust of banks. Information or knowledge gaps may also be to blame. After all, it is hard to ask someone to trust something they do not know or barely understand.

The current state of financial literacy in the region is disappointing. According to a survey by García et al., (2013), the majority of the population in Chile, Colombia, Guatemala, Mexico, and Peru does not understand the term "interest rate." Inflation is another highly misunderstood concept, and thus very few people understand how to factor it into their calculations of the purchasing power of money.

Theoretically, reducing informational gaps should boost the use of formal saving products. However, the actual effect may be disappointing. Survey experiments conducted in Peru, Mexico, and Brazil evaluated the impact of providing poor and middle-income households with information on bank products and yields on the hypothetical choice of opening a formal savings account (Frisancho and Karver, 2016). In all cases, the effect was modest at best.

In general, the effectiveness of interventions to improve financial literacy is discouraging, beyond a few notable exceptions (see Fernandes, Lynch, and Netemeyer, 2014). Traditional financial literacy interventions may be failing not because of the content but because 
of the delivery strategies used. Standard classroom-like delivery methods have not worked well, but simpler and more agile financial literacy interventions seem promising. Drexler, Fischer, and Schoar (2014) compare two distinct financial literacy programs aimed at microentrepreneurs in the Dominican Republic. The first followed traditional financial education modules in a classroom-like environment. The second was a simplified "rule-of-thumb" program. While the standard accounting program had almost no effect on business financial and profit outcomes, the simplified training resulted in better accounting practices and higher profits.

All in all, the most effective policy by far to increase access to formal saving instruments is removing initial transactional barriers. However, while policy interventions that help reduce transaction costs are effective in persuading people to open accounts, they are far less so in convincing people to use them (see Frisancho, 2016). Most likely, other factors affect household saving decisions more generally. To understand this side of the problem requires nothing less than looking into the minds of Latin American savers and analyzing their cultural and personal biasesa formidable task indeed.

\section{In the Hearts and Minds of Savers}

\section{Family and Friends First}

It's hard to say no to a family member in need, especially in a culture like that of Latin America that places a high value on the extended family. Despite the insurance benefits that extended networks of family and friends may offer, they can also represent a drain on a household's time and resources and ultimately impose demands on their accumulated stock of savings. These demands are particularly high in Latin America, where private transfers among households represent, on average, 36 percent of per capita labor income (Lee and Mason, 2011a). ${ }^{4}$ The high rate of private transfers may also explain the small balances but large cash flows that the relatively poor manage (see Chapter 2). Moreover, the poor spend considerable sums on weddings, festivities, and funeralscelebrations that often include their extended family and/or their social network of friends and neighbors (Collins et al., 2010 and Banerjee and Duflo, 2007). Social pressure to share income and assets may discourage asset accumulation, encourage a fast turnover of resources, or even 
induce costly behavior such as strategic borrowing to hide resources and preempt requests for transfers (Baland, Guirkinger, and Mali, 2011).

Latin America is not the only place where social pressure affects portfolio allocation (Jakiela and Ozier, 2016). In Kenya, villagers were randomly assigned an initial sum of money and asked to put that money in either a savings account with private balances or an investment account. In the case of the investment accounts, information about their returns could be either public or private, or they could pay a fee to keep the information private. Women, but not men, were willing to forego expected income in order to keep their returns a secret from others in their village. Women with large sums of money and public returns invested 6.5 percent less in a business opportunity than women with less money who could keep the returns private. Essentially, the study finds that women face an average "kinship" tax of about 4 percent of income. ${ }^{5}$

The burden that a social network imposes can be hard to escape. Fear of social shame and ostracism, as well as reciprocity, can be great, especially in close-knit communities. In India, the extent to which households help each other financially, and thus provide interpersonal insurance, varies with social proximity (Chandrasekhar, Kinnan, and Larreguy, 2012). Among very connected households, the level of transfers does not change when a savings instrument is provided. Essentially, family and friends trump personal savings and investment. Thus, the demands of social networks limit the stock of savings the poor can accumulate and divert resources away from productive uses.

In addition to pressure across households, tension between members of the same household also constrains saving. More than one marriage has been strained when one partner makes monetary choices for the household. The reasons for this tension stem from differences between spouses in terms of their bargaining power, intertemporal preferences (Schaner, 2015; Browning, 2000), risk tolerance, or even tastes in consumer goods (Anderson and Baland, 2002). Strategic behavior by both partners can lead to inefficient saving choices.

Differences in saving goals within a household may be explained by differences in the rate at which husbands and wives discount the future. Since women live longer than men and tend to be younger than their husbands, they may well have lower discount rates (Browning, 2000). The prospect of a longer retirement period without their husbands drives women to save more for old age. 
In Latin America and the Caribbean, women live an average of 73 years, while men live only 68.9 years. This gap is even wider among developing countries within the region, with females living 77.7 years and males $71 .{ }^{6}$ Moreover, women in Latin America tend to marry older men. Among couples with husbands aged between 30 and 50, irrespective of the number of children, about half the households in Brazil consist of husbands who are four or more years older than their wives-almost double the share of households with wives who are the same age or older than their husbands (see Table 9.1). The age gap is similar in Mexico and somewhat less skewed in Peru, but still relatively high.

Viewing households as groups of individuals helps explain the risk sharing arrangements that take place within the unit. By definition, twoperson households face less income risk than single-person households dependent on a single source of income. If someone at home loses his or her job, two-person households have to adjust their consumption less than single-person households. In the same vein, two-person households are less affected by the removal of public insurance, such as unemployment insurance, both in terms of savings and the accumulation of assets. Multiple-person households can indeed insure their members by strategizing over labor supply (who in the household will work, at what kinds of work, and when) depending on the generosity of the public insurance available. ${ }^{7}$

In sum, decision-making both within and across households and intra-household insurance mechanisms may lead to suboptimal saving choices. Although it is hard to tackle these issues directly when they constrain saving, they need to be considered in the design of financial services and public insurance programs. For example, in settings where pressure to share with other family members or friends is high, hard

Table 9.1 Age Differences between Wives and Husbands (percent of households)

\begin{tabular}{|c|c|c|c|c|c|c|}
\hline \multirow[b]{2}{*}{ Age difference } & \multicolumn{2}{|c|}{ Peru } & \multicolumn{2}{|c|}{ Mexico } & \multicolumn{2}{|c|}{ Brazil } \\
\hline & $\begin{array}{c}\text { No } \\
\text { children }\end{array}$ & Children & $\begin{array}{c}\text { No } \\
\text { children }\end{array}$ & Children & $\begin{array}{c}\text { No } \\
\text { children }\end{array}$ & Children \\
\hline Wife older & 24.1 & 16.4 & 16.2 & 17.9 & 17.9 & 16.5 \\
\hline Same age & 12.9 & 12.9 & 10.5 & 10.4 & 6.8 & 8.4 \\
\hline Husband $1-3$ years older & 26.3 & 26.8 & 33.1 & 31.3 & 26.5 & 26.3 \\
\hline Husband $4-5$ years older & 12.1 & 13.9 & 12.7 & 13.5 & 15.5 & 13.5 \\
\hline Husband more than 5 years older & 24.5 & 30.0 & 27.5 & 26.9 & 33.3 & 35.2 \\
\hline
\end{tabular}

Source: Authors' calculations based on the Base of Pyramid (BoP) Survey. 
commitment saving accounts can be useful instruments for households trying to accumulate a stock of savings (Brune et al., 2015).

\section{A Behavioral Economics Tale}

Even if there were no constraints to saving formally, saving levels could still suffer if individual biases influenced saving choices. Ultimately, saving is a personal decision subject to an individual's needs, wants, and even personality.

\section{The Penchant for Instant Gratification}

The economics and psychology literature have both documented the importance of time preferences in saving decisions (Frederick, Loewenstein, and O'Donoghue, 2002; DellaVigna, 2009). Individuals with present-biased preferences find it extremely hard to postpone consumption, even if it comes at the expense of their future welfare. Thus, they consume today, instead of saving for tomorrow. The more immediate the reward, the harder it is for them to postpone consumption: that is, their preferences may be time-inconsistent. Preferences of this sort lead people to procrastinate in various aspects of their lives: starting a diet, writing a boring report, or renewing a driver's license. They find it particularly hard to save whenever self-control mechanisms are not incorporated into their choices.

Several recent studies have tried to measure the correlation of present-biased preferences with under-saving. These efforts have typically involved small sample sizes in randomized controlled trials or case studies. A noteworthy exception is Wang, Rieger, and Hens (2011), who measure impatience and time discounting in 45 countries, though still relying on small samples of university students (see Box 9.1).

Time preferences may vary by nation or region. Using nationally representative data at the urban level for Peru, Mexico, and Brazil, Frisancho and Karver (2016) measure time preferences by asking individuals to hypothetically choose between a small reward today and a larger one in a month. They then compare their answers for the same question but set in a more distant time frame, six to seven months from now. Individuals who choose the smaller reward now rather than waiting for a larger reward in a month, but claim that they would be willing to wait for the larger reward six months from now, are considered time-inconsistent. ${ }^{8}$ About 40 percent of the urban population in Mexico, Peru, and Brazil has 
time-inconsistent preferences. More importantly, about one-third of the urban population in these countries can be considered hyperbolic discounters: they penalize the passage of time more strongly today than they do in the future (see Frisancho and Karver [2016] for more details).

Hyperbolic discounters have a harder time saving because of their present-biased preferences. They also may be more likely to borrow whenever they need cash. In Peru, hyperbolic discounters are 14 percentage points less likely to save than people who are always patient. In Mexico, hyperbolic discounters are 10 percentage points more likely to be indebted than those who are consistently patient. In Brazil, the probability of saving is 8 percentage points lower for hyperbolic discounters relative to people who are always patient (Frisancho and Karver, 2016).

Overall, an important share of the population in Latin America and the Caribbean may benefit from commitment devices that help them save. Those who are conscious of their present-biased preferences will actively demand financial products that help them exercise self-control-like individuals who find a "gym buddy" to motivate them to exercise. People who are not fully aware of these biases could also benefit by being presented with default or opt-out schemes since procrastination itself and/ or inertia will deter or at least delay an active choice to opt out (DellaVigna and Malmendier, 2006). Mandatory pension plans are in essence a way to deal with the tendency to postpone saving for retirement.

Helping people deal with their self-control problems is effective at increasing saving. ${ }^{9}$ Since time-inconsistent individuals face a disconnect between their present self and their future self, they need a commitment device to keep up with their initial savings plan. The commitment device can include penalties, such as interest rate reductions or fees. A seminal study by Thaler and Benartzi (2004) shows that behavioral economics can be effectively used to design prescriptive policies: by offering people the option to commit in advance to allocating a portion of their future salary increases toward retirement savings, the program "Save More Tomorrow ${ }^{\mathrm{TM} \text { " }}$ increased saving rates from 3.5 percent to 13.6 percent in a span of 40 months.

A commitment product provided by a bank in the Philippines allowed savers to choose between time-based and amount-based maturities. Among those who opened the account, saving balances increased by over 300 percent relative to the control group. Not surprisingly, savings increased the most among those initially identified as time-inconsistent. These people are precisely the ones whose time preferences are more 
likely to limit their saving choices in the absence of a commitment device (Ashraf, Karlan, and Yin, 2006).

In settings where the supply of formal products is limited, commitment devices may take the form of informal arrangements, such as saving groups or rotating saving and credit associations (ROSCAs). ${ }^{10}$ Members meet to make regular lump-sum contributions that they pool and give to one member of the group in each meeting. These groups are usually formed within an existing social network, which guarantees that the imposed commitment is binding. In Chile, such self-help peer groups were implemented among microentrepreneurs as a commitment device to encourage precautionary savings (Kast, Meier, and Pomeranz, 2012). The number of deposits grew by about 350 percent and savings balances almost doubled among clients in the treatment group.

How strong should the commitments be? Imposing liquidity restrictions that are too strict runs the risk of scaring participants away (Ashraf, Karlan, and Yin, 2006). The trade-off between commitment and flexibility is a recurring issue in the design of financial products and services. Although there is a demand for products that tie one's hands in the future so he can reach his current saving goals, unexpected shocks may force households to break their commitment. In such cases, strong commitment devices may even reduce welfare. The right balance between commitment and flexibility is hard to strike and depends on the setting as well as the specific saving motives of the targeted population and their exposure to uninsured risks. For instance, strong commitment accounts may be more suitable for saving for a specific goal or a planned expenditure/investment, rather than simply for a rainy day (Dupas and Robinson, 2013b).

Commercial commitment products being developed in the region contain a contract specifying a savings plan with a goal to be achieved in a fixed number of installments. Additional incentives are usually offered for those who keep up with their plan, such as preferential interest rates or participation in raffles. Although penalties can also be used to deter individuals from missing an installment, these are rarely implemented, especially when the product is first launched. While some products involve a social commitment, many others rely on individual commitments and/or labelling to help users follow their saving plan. ${ }^{11}$

The Multilateral Investment Fund (MIF) has been promoting individual scheduled saving accounts in the region with varying degrees of commitments and rewards. ${ }^{12}$ Preliminary results suggest that take-up 
rates for commitment devices are high, but usage tends to decline over time. Procrastination or lack of attention reduces the incentives to make deposits over time. Thus, to ensure that people continue to make deposits, they may need additional features built into the product. Using reminders or capitalizing on some of the problem-solving biases discussed in the next section, such as inertia, may be effective tools to increase saving balances among households in the region. ${ }^{13}$

\section{Inertia and Limited Attention: Not All Bad}

Most economic models assume that people process all available information in a rational and optimal way. But in real life, people make bad (and conscious) choices. Does this mean they are not rational optimizing agents?

Not necessarily. Psychological or cognitive biases also affect decisions. Sometimes people use less information than is available because it is hard to process-especially when a choice is urgent. Other times, people may act on hunches just because they are overconfident about their own opinion on a given matter. In other words, individuals tend to make decisions based on mental "rules of thumb," or heuristics (Kahneman, Slovic, and Tversky, 1982). ${ }^{14}$

Two such psychological biases are important determinants of saving behavior: inertia and limited attention. The first emerges from a preference for the status quo: the current state is perceived as a reference point and any deviation from it is perceived as a loss. Whenever taking an action imposes some sort of transaction cost, people who prefer the status quo (a tendency toward cognitive inertia) will have a harder time incurring that cost.

Preferences characterized by inertia lead to habits. Some people tend to go to the same places and order the same dishes when they go out for lunch or dinner, for example. These are safe choices; they repeat them because they represent the status quo and they are satisfied with the outcome. Finding a new place to eat or trying a new dish incurs a search cost and poses the risk of not liking the new choice, so there is a tendency not to change. This is why automatic enrollment plans have been successful in many settings, especially in consumer markets. Many promotional campaigns provide a given good or service at a reduced rate for a short period of time, after which automatic enrollment kicks in at the regular rate. Surprisingly, many individuals find it easier to keep paying the higher price than to cancel the service. 
Limited attention can also lead to poor choices if information is neglected. In many countries, for example, retail stores must list the final price of their products, including taxes. This is a common practice because consumers tend to forget to factor in the additional cost of taxes when buying goods.

When individuals succumb to limited or selective attention, they are more prone to make mistakes or distort their choices. People can have trouble forecasting their future expenditures, for example, which can affect their saving behavior. Planning tools that force people to list all the elements of their household consumption basket, for instance, can help them pay attention to frequently overlooked details when forecasting their consumption. Evidence from Frisancho and Karver (2016) provides an example along these lines. Households were asked two different questions: "Do you or anyone in the household save regularly?" and "In the last 12 months, have you or anyone in the household saved using [...formal/informal saving instruments...]." Notably, households respond very differently to these two questions. When asked about whether they save in general, households misreport their actual saving behavior. Among those who claim not to save in general, 39 percent, 23 percent, and 15 percent of the households in Peru, Mexico, and Brazil, respectively, report saving when asked whether they use each possible financial instrument, one at a time.

Inertia and limited attention need not work against saving activity. On the contrary, they can be tapped to actually boost saving levels. First, capitalizing on inertia, the optimal saving level can be made the default. Individuals who tend to prefer the status quo find it harder to opt out of saving. In this way, inertia serves as a constraint for the person to stop saving. Automatic discounts or direct deposits may help mobilize savings in settings where income flows, such as wages, are intermediated by some individual or institution other than the saver. Contributions to pension plans intermediated through the employer seize this opportunity to help people save for retirement. Banks in more financially developed settings have incorporated this feature into several commercial products: an example is automatic deductions for savings for individuals who receive their wages through a bank transfer.

The scant use of electronic transactions as a means of payment in developing countries limits the possibility of using default mechanisms to encourage savings. Nevertheless, recent efforts in the region have targeted cash transfer beneficiaries who receive their grants via direct deposit to 
a bank account. Default devices linked to remittance receipts is another effective way to capitalize on inertia, since remittance recipients tend to receive an international wire transfer on a regular basis. Whenever income flows through a bank account, additional illiquid accounts can be linked to it to allow the recipient to choose automatic discounts to be saved.

The saving potential of such mechanisms is highlighted by a recent study on the effects of offering direct deposits of the proceeds from cash crop harvests in bank accounts in rural Malawi (Brune et al., 2015). Almost 300 farmers' clubs, each with 10 to 20 members, were randomly assigned to a control group or one of two treatment arms: a direct deposit account and a commitment saving account. The second arm offered the direct deposit account but added an additional illiquid account that allowed farmers to specify an amount to be transferred into it, as well as date-based maturity. Both treatment arms helped increase total savings balances, since all cash crop earnings were automatically saved. However, the commitment account had a much larger effect: while the direct deposit account increased total balances by 280 percent, savings increased 620 percent with the commitment account.

Inertia can also be capitalized on by promoting saving habits among children and youth. Instilling saving habits at a young age can generate new reference points or a status quo that incorporates saving in consumption decisions. Showing young people the value of delaying gratification could be a promising strategy to promote higher savings in Latin America and the Caribbean, where time preferences are biased more toward the present than in other regions.

Financial education for youth can yield important indirect effects beyond financial knowledge, attitudes, and outcomes. First, good financial habits are also linked to better outcomes in schooling, employment, and standards of living. Second, young people can be agents of change in their households, sharing knowledge they acquire with their parents and other siblings (Bruhn et al., 2013).

In Brazil, a financial education program in public high schools improved financial literacy. More importantly, the program seems to have benefited all students, irrespective of their initial level of performance in a financial knowledge exam. Students in the treatment group were on average 12.5 percent more likely to save than the control group. The intervention also improved spending behavior: students in the treatment group were more likely to compare prices, or negotiate prices or payment methods while shopping, and prepare monthly budgets. 
Finally, the program also seems to have "trickle up" effects: parents in the treatment group scored higher in a financial literacy exam and were more likely to save (Bruhn et al., 2013).

A recent experiment with young account holders in Colombia explores the roles of limited information, limited self-control, and limited attention on saving behavior with a financial information campaign delivered through short message service (SMS) (Rodríguez and Saavedra, 2015). A large-scale field experiment included three treatment arms in addition to a control group: a financial education campaign with monthly messages; and two treatments with monthly and bimonthly reminders to save. The better targeted reminders to save, regardless of their frequency, had important effects on account balances, mainly by reducing withdrawals. The financial knowledge campaign had no significant effect on account balances, which suggests that informational and knowledge constraints were not binding in this sample. ${ }^{15}$

Lack of attention can also be tackled with appropriate reminders and nudges that help people achieve their saving goals. In daily life, people who know they have a bad memory or lack attention resort to simple tricks to remind themselves of certain events or tasks: wearing a rubber band around their wrists, writing reminders on their hands or arms, placing Post-It notes on the bathroom mirror, or writing to-do lists. Similar strategies may work when it comes to savings. In Bolivia, Peru, and the Philippines, reminders with varying content helped achieve a 6 percent increase in saving balances and a 3 percentage point increase in the probability of reaching a given saving goal (Karlan et al., forthcoming). ${ }^{16}$

The timing and frequency of nudges or reminders may also be important. Certain times of the month or day may be better than others for reminding people to save. If, for instance, the household receives the reminder when cash is scarce, the impact of the nudge could be weak. There may be better times of the day to remind people about their excessive expenditures and their saving goals, such as lunch or dinner time. In some cases, a one-time reminder may not be enough; if so, how many are effective? Finding the right balance between too few reminders and potential "harassment" is another important avenue for future research.

\section{Policy Recommendations: What Really Counts}

This chapter suggests three main strategies to promote household saving. First, there is a clear need for financial product innovation in the 
region to encourage more saving, particularly via formal channels. For example, social constraints to save need to be considered in the design of financial services. Behavioral biases, which also constrain saving for a large share of the population, should also be incorporated in the design of financial products and services.

Second, formal institutions can and should learn from informal mechanisms currently serving the financial needs of poor households. These informal arrangements have emerged to cover the unmet needs of those excluded (and those who exclude themselves) from formal financial services. Formalizing informal mechanisms whenever possible or through potential partnerships with formal institutions can help attract savings into the formal financial system.

Third, focusing on children and youth can foster positive saving habits and potentially affect preferences that could increase saving rates in the future. Since some of the traits that limit saving choices are malleable at younger ages but hard to modify in adults, early interventions may be able to impact time preferences and saving behavior. Given limited empirical evidence, more research is needed, and the research agenda needs to incorporate input from other fields such as neuroscience and psychology.

\section{Product Innovation}

\section{Keep It Simple}

"The simpler a task, the more likely it is to be done," conclude Karlan, Ratan, and Zinman (2014). Complicated paperwork, hidden fees, long lines to make a deposit, and burdensome trips to the bank all discourage clients from opening an account and/or continuing to use it. In a region where financial literacy is particularly low, financial institutions need to simplify processes to close information gaps that can limit the demand for saving services.

\section{Tackle Behavioral Biases}

About one-third of the population in urban Peru, Brazil, and Mexico exhibits hyperbolic time preferences. Moreover, according to the experimental evidence of Wang, Rieger, and Hens (2011) (see Box 9.1), the prevalence of present-biased preferences is higher in Latin America and the Caribbean 
than in other regions. People with behavioral biases would benefit from commitment devices that would help them save. Consumers who are aware of these behavioral biases have tried to find informal or idiosyncratic ways to deal with them via informal saving mechanisms such as ROSCAs. Formal suppliers of financial services could cater to time-inconsistent consumers with products that help them keep up with their saving goals. Scheduled saving plans and commitment accounts that correctly balance incentives and penalties could be effective instruments to bank the unbanked and help them increase their saving balances.

Among consumers who are not aware of their behavioral biases, introducing default mechanisms in developing financial markets could help them reach their goals. However, the advantages of these mechanisms can be better exploited in settings where income flows are intermediated through formal financial systems. Policymakers and financial institutions that join forces to bank the unbanked are thus a crucial foundation for providing saving products that respond to the needs of the households in the region.

\section{Incorporate Technology}

Technology can be helpful not only to simplify processes and transactions but also to help individuals deal with their behavioral biases. Opening accounts and being able to manage them online, for example, may lead to higher take-up and usage rates. Cellphones and the internet facilitate transactions that could otherwise be postponed indefinitely by time-inconsistent individuals. Transferring money from a simplified account to a more illiquid one with a couple of clicks minimizes the role that behavioral biases may play.

Technology can also aid with reminders. The ubiquity of cellphones in the region makes text messages and mobile application software the ideal cost-effective channel to help people save.

Nevertheless, regulation must catch up with innovation. The onus is on financial regulators to ensure that local regulations do not deter the development of new saving products that rely on technology.

\section{Keep Testing}

High-income households in Latin America and the Caribbean save a relatively higher fraction of their incomes than poorer households 


\section{BOX 9.1. DO GENES AND CULTURE MATTER FOR SAVING?}

Several studies have probed differences in saving behaviors across countries and agents to understand if there is a natural propensity to save. A series of studies in the 1970s used factor models to decompose the variance in IQ tests into its genetic and environmental components. However, estimates of the contribution of genetic components from this literature range widely and depend mainly on strong and restrictive assumptions about the factor loadings or about the distribution of the genetic and environmental components. ${ }^{\text {a }}$

A noteworthy study on the role of genetics in saving decisions was recently conducted by Cronqvist and Siegel (2015) in Sweden. By exploiting the differences in genes shared among fraternal and identical twins, the study finds that genetic differences explain about one-third of the variation in individual savings rates. Moreover, the study finds that saving rates are negatively correlated with smoking and obesity-behaviors that may also reflect lack of self-control and present-biased preferences-and that this correlation is largely explained by genetic factors.

Another innovative strand of the literature has focused on testing what is referred to as "linguistic relativity," or the Sapir-Whorf hypothesis: Does the structure of a language affect the ways in which its speakers view the world? Can language influence the way speakers think and/or engage in nonlinguistic behaviors such as saving? A recent study by Chen (2013) evaluates whether speakers of languages that disassociate the present from the future have a harder time saving. He first classifies languages into strong and weak futuretime reference (FTR) languages, and finds that Spanish and English have strong future time-references, while Chinese has a weak one. ${ }^{b}$ In other words, Chinese distinguish the differences between current and future events less strongly than Colombians, who tend to make a very clear distinction between the two.

With this language coding in hand, Chen (2013) finds that the degree of future-time references intrinsic in each language correlates highly with the way in which speakers deal with household and individual intertemporal decisions such as health and saving choices. Furthermore, he shows that linguistic relativity may play an important role in national saving rates: countries with a strong FTR language save about 5 percentage points less per year than comparable countries with weak FTR languages.

Wang, Rieger, and Hens (2011) measure long-term discount rates $(\delta)$ and present-bias discount factors $(\beta)$ in 45 countries around the world. Whenever $\delta=1$, individuals give the same weight to gains/losses today and tomorrow; i.e., they do not penalize future events. Thus, low values of $\delta$ signify that they discount the future more heavily relative to the present. Individuals may also discount the future against the present differently depending on when the choice is made. Someone may care about an intertemporal trade-off between today and a week from now, but not so much between four and five weeks from now. Individuals with $\beta=1$, will not exhibit any present bias in their choices 
BOX 9.1. (continued)

Table B.9.1 Median Long-Term and Present-Bias Discount Factors

\begin{tabular}{lcc}
\hline & Long-term discount factor $(\boldsymbol{\delta})$ & Present-bias discount factor $(\beta)$ \\
\hline Anglo & 0.84 & 0.76 \\
\hline Middle East & 0.80 & 0.62 \\
\hline East Asia & 0.84 & 0.65 \\
Latin Europe & 0.82 & 0.60 \\
\hline Latin America & 0.82 & 0.59 \\
Germanic-Nordic & 0.84 & 0.60 \\
\hline Africa & 0.77 & 0.43 \\
East Europe & 0.79 & 0.38 \\
\hline
\end{tabular}

Source: Authors' calculations based on Wang, Rieger, and Hens (2011).

Note: The Anglo region includes Australia, United Kingdom, Ireland, New Zealand, Canada, and the United States. Latin Europe includes France, Portugal, Italy, and Spain.

and will evaluate intertemporal trade-offs in the same light, irrespective of the time for receiving the reward/punishment.

Table B9.1 summarizes the study's results. When grouped by cultural clusters, the median values of the long-term discount rate $(\delta)$ remain quite stable across regions, mostly around 0.8. The only exception is Africa, which has a slightly smaller discount factor of 0.77 , signaling a less patient attitude in the long term, which is consistent with very low levels of development in the continent. By contrast, there is a great deal of variation in the present-bias discount rate $(\beta)$ across different cultural clusters. While Latin America and the Caribbean and East Asia have similar long-term discount rates, their present-bias discount rates differ. Latin Americans have a higher prevalence of present-biased preferences. The difference in median $\beta$ between Latin America and the Caribbean and Anglo cultures is even greater: present-bias discount factors among the latter are almost 30 percent higher than in Latin America and the Caribbean.

a For a thorough survey and critique of these studies, see Goldberger (1979).

${ }^{b}$ By contrast, in other Asian countries where multiple languages are spoken, such as Singapore and Malaysia, the main language spoken has a strong future-time reference.

(Chapter 2). This is particularly worrisome because lower income households face greater exclusion from credit and insurance markets, higher income volatility, and greater vulnerability to unexpected income shocks. The poor are also relatively more constrained than the rich in their access to formal saving products due to the higher burden imposed on them by monetary costs or by lower levels of financial literacy.

However, developing and testing prototypes of formal saving products to reach and be used by the poor may not be an appealing 
enterprise for traditional financial institutions, and it may be extremely costly for nonprofit microfinance institutions that are struggling to survive. After all, the savings that the poor can mobilize amount to modest aggregate sums. This knowledge gap has been more or less covered by the academic community, whose interest in prototypes is increasing, and extensive randomized control trials all over the developing world. Nevertheless, academics' incentives to publish and practitioners' urge to find timely solutions that can be cheaply and quickly tested can limit the extent of experimenting that takes place.

Some efforts to coordinate these two sets of actors have emerged in the past few years. Innovation for Poverty Actions (IPA) has been active in promoting financial inclusion. It has launched several initiatives to connect policymakers and practitioners (matchmaking gatherings) and promote timely research to inform financial inclusion efforts in the developing world. The Multilateral Investment Fund has also served as a laboratory to test financial products and services in the region, with a stronger emphasis on saving products in recent years. As the region and the world as a whole keep changing, these initiatives will be crucial for informing policymakers, practitioners, and financial institutions.

\section{Bridging the Gap between Informal and Formal Mechanisms}

Households excluded from formal financial markets meet their demand for financial services by relying on informal mechanisms that are frequently linked to social networks. Although these informal services often charge very high fees and, in some cases, are insecure and unreliable, they remain popular. Some households may even prefer informal services over formal ones for a variety of reasons, such as their convenience, ease of use, and trustworthiness (Lee, Ainslie, and Fathallah, 2012). Providers of informal saving or credit instruments are usually already present in the clients' social network, so access to them is extremely convenient. Moreover, transactions tend to occur without the hassle of paperwork or complicated contracts and are usually enforced by social norms. Despite the risk involved in these unregulated transactions, households seem to perceive them as safer than those in the formal financial systems. These preferences may reflect their distrust of banks and/or confusion and disinformation about regulations and fee structures. 
In reality, informal instruments can be very costly or unsafe due to the demands of family and friends and the high probability of loss or theft. Moreover, informal mechanisms tend to be very illiquid as in the case of saving groups or ROSCAS, where the saver must wait until luck or a predetermined schedule of payouts determine if it is his or her turn to receive the pot.

Beyond their proximity to unbanked clients, informal services have several other advantages when reaching the unbanked. They tend to be very flexible and innovative, as they emerge and adapt to the specific needs of the population they serve (Pagura, 2008). Susu collectors in Africa, for example, charge a fee to collect very small deposits over the course of a month (sometimes daily) and keep them safe. Households demand these services-which are prohibitively costly for a formal institution to supply-as a way to self-impose a commitment device to save or to keep savings out of the hands of family or friends.

Although financial inclusion efforts tend to focus on providing formal financial services, formal financial institutions are starting to link up with informal providers so they can reach clients they would otherwise find extremely hard to serve due to lack of infrastructure and local knowledge.

The "informalization" of formal financial services is happening around the world. In Ghana, two private banks are using susu collectors to mobilize savings, while in Jamaica, the Workers Bank created a product that mimics ROSCAs. In the Philippines, formal sector banks extend loans to informal lenders, creating a system of credit-layering that allows them to increase their outreach in rural settings by reducing problems of information, monitoring, and enforcement (Floro and Ray, 1997). In Bolivia, a nonregulated microfinance institution providing nonfinancial services to its clients created over 20 linkages with a variety of actors, including private sector firms such as Western Union and utilities companies. The microfinance institution was then an effective means for formal institutions to reach rural populations (González-Vega and Quirós, 2008).

Even though banking low-income populations may not be profitable per se, banks are realizing that supplying additional financial instruments such as credit and insurance is a very attractive business opportunity. Their ability to serve the poor on a large scale can thus become profitable. After all, the poor are an important share of the population in Latin America and the Caribbean: between 60 percent and 70 percent of the population lives on less than US\$10 a day (in purchasing power parity terms). 
Formal providers willing to go the extra mile may learn from the successful experiences of informal providers of financial services. First, banks can build on the existing supply of informal financial services. This strategy may help generate trust among unbanked clients, which is an important access barrier in the region.

Second, formal financial institutions can find ways to extend their outreach by merging with or sponsoring other informal providers that have comparative advantages in the market. The formalization of these providers can help reduce the risks and insecurities associated with informal mechanisms. These alliances can also help formal institutions reduce the upfront information and search costs that bancarizing entails. ${ }^{17}$ Partnerships with informal institutions that have already assumed the sunk costs of banking someone (including educating the client and building a credit history) may reduce the costs of formal providers trying to reach the unbanked.

Finally, the design of formal products should be inspired by informal products currently being offered, which have been directly shaped by people's demands over time.

\section{Getting an Early Start}

Given the importance of behavioral biases to saving, directing interventions at children makes sense. Influencing the behavior of children is certainly easier than changing the bad habits of adults. Evidence from developmental psychology and neuroscience (Henrichs and Van den Bergh, 2015) indicates that self-regulation or self-control is governed by the prefrontal cortex, which can start to develop as early as in utero and continues into early adulthood. Environmental factors can influence both gene expression and neural specialization (Meaney and Szyf, 2005; Henrichs and Van den Bergh, 2015); this opens up the possibility of conducting early interventions among children and youth, while the prefrontal cortex is still developing. Self-control is an important trait for humans in many dimensions of their lives well beyond saving choices; it is thus urgent to learn about interventions that are successful in mediating the perverse effects of genetic predispositions.

However, empirical evidence on interventions that can either generate supportive environments for young people with a higher propensity to save or minimize the effects of genetic predispositions to save little is still scarce. Some exceptions are found in Jamison, Karlan, and Zinman 
(2014), Karlan and Linden (2014), and Berry, Karlan, and Pradhan (2012), but their results are far from promising.

Brazil is including financial education in the curriculum of public high schools in the context of a National Strategy for Financial Education (ENEF). Initial results are promising (Bruhn et al., 2013). Several governments in Latin America and the Caribbean are following suit. Education ministers have yet to explore the best way to develop the specific financial literacy component to be included in the public high school curriculum, as well as adequate teaching materials.

Modifying time-preferences or saving attitudes to increase the propensity to save is not an easy task. Little is known about the best time to get started (whether with younger children in primary school and/or older children in secondary school); the length of exposure to environments that are conducive to improving self-control; or the experiences that moderate propensities to save, among others.

Pioneering work along these lines is being undertaken by some nonprofit microfinance institutions in the region, including FINCA Peru and ADRA Peru (see Box 9.2). Monitoring, evaluating, and experimenting along the lines of these efforts is crucial to better understand the impact that early interventions may have on saving choices. More research on the intersection of economics, neuroscience, and psychology is also needed to better understand the effects of environmental factors on genetic traits.

\section{Redefining Financial Inclusion}

Financial inclusion has often been viewed narrowly as households' ability to obtain access to credit. For decades, MFIs focused their efforts on easing the credit constraints of poorer households that lacked access to formal financial systems (Angelucci, Karlan, and Zinman, 2015; Banerjee et al., 2015; Banerjee, Karlan, and Zinman, 2015). In recent years, however, the concept of financial inclusion has expanded. Financial inclusion efforts now recognize the role of savings as a development tool and understand that households face strong constraints to save.

The initial focus of financial inclusion was on lifting supply-side constraints by trying to expand the use of formal financial services among the unbanked. Around the developing world, governments energetically promoted simplified saving accounts. ${ }^{18}$ These efforts have helped bank the unbanked. However, demand-side constraints also restrict 


\section{BOX 9.2. IN PERU, NEVER TOO YOUNG TO SAVE}

Microfinance institutions in Latin America and the Caribbean have usually promoted the development of saving habits among their clients, who are primarily female microentrepreneurs. In recent years, some institutions have extended their focus to the children and grandchildren of these women by providing programs and products designed to help children save. In Peru, for example, FINCA Peru has implemented a program developed by the nongovernmental organization Aflatoun in rural areas for primary and secondary students and is providing saving instruments to their clients' children.

Another example in Peru's peri-urban and rural areas is the village banking program of the Adventist Development and Relief Agency (ADRA). After a few years as a pilot, the institution launched a product designed to teach children saving habits by directly helping them save. The product is offered to their clients' children and grandchildren aged 0 to 18. Children who participate choose a specific saving goal, label a moneybox provided by ADRA with their goal, and start a cycle of monthly deposits during the village bank meetings. The children cannot withdraw their funds until they have reached their goal. In the meantime, they earn interest, as the funds can be used to extend loans to bank members. The moneyboxes help the children achieve their goals and avoid temptations to withdraw funds between deposits. ADRA also offers a training component for the children's mothers and grandmothers that emphasizes the crucial role they play in promoting their children's saving habits.

Although the effect of the program has not been evaluated, the rapid expansion of the portfolio of young clients is encouraging. Between December 2012 and June 2015, the number of children in the program grew from 882 to 3,831 , and total savings accumulated by these young clients increased sixfold. As of June 2015, the average stock of savings per child was about US\$28.

households' ability to save-particularly through formal instruments. Even when households have a bank account, they may be unable to reach their saving goals because of demand-side constraints, such as social pressure to lend to friends and family, lack of knowledge and/or information, and behavioral biases.

Any national financial inclusion strategy that seeks to go beyond counting the number of accounts opened must consider the factors that limit household savings. On the one hand, formal financial institutions should continue to design simple, easy-to-use saving products that meet the demands of households. On the other hand, financial services must take into account the interaction between saving and credit constraints in a given market, and the effects on households' financial portfolios 
and their demand for financial services. Although credit and saving are often viewed as opposites, they are really two sides of the same coin: households choose to save and borrow simultaneously. When households need money, both instruments provide a tool to finance lump-sum expenditures, since they both require a regular schedule of deposits and facilitate a single withdrawal at a given point in time (Afzal et al., 2015).

Dealing with saving barriers is harder than expanding the presence of banks through agent banking services. Demand-side constraints require well-crafted policy interventions capable of altering behavior. Affecting people's beliefs and preferences is not an easy task, but the potential returns of such interventions may be large-for individuals, households, and the development of their countries. 


\section{Notes}

1 Frisancho (2016) summarizes recent experimental evidence on interventions that tackle a variety of saving constraints discussed in this subsection, including transaction costs, lack of trust and regulation, information and knowledge gaps, social pressure and behavioral biases.

2 See Chapters 3 and 11 for an overview of the main factors that drive up bank costs in Latin America and the Caribbean.

3 See Chapter 11 for other issues related to regulation barriers.

4 Nearly two-thirds (65 percent) of the annual consumption of people under 24 in Latin America and the Caribbean is financed by other members of the household, according to National Transfer Account (NTA)'s data. The elderly, on the other hand, give up $12 \%$ of their annual consumption in the form of private transfers (see http:// www.ntaccounts.org/doc/repository/NTA\%20Data\%20Sheet.pdf).

5 These conclusions are drawn from an experiment in Kenya by Jakiela and Ozier (2016). Preliminary results from a similar experiment in Senegal confirm these patterns (Boltz, Marazyan, and Villar, 2015). Data from the World Bank's World Development Indicators.

7 See Ortigueira and Siassi (2013) for more details on an intra-household insurance model.

8 A word of caution is in order. Janssens, Kramer, and Swart (2015) discuss in detail the problems that arise when measuring hyperbolic discounting through hypothetical choices in a one-time cross section. They argue that agents' level of patience may change because their preferences are unstable over time rather than because of present-bias. To measure time inconsistency accurately, the authors recommend relying on a longitudinal design that allows stationarity, time consistency, and time invariance to be disentangled. To the extent that agents incorporate the probability of changing environments in their answers to one-time experiments, future efforts to measure time inconsistency should rely on longitudinal data when possible.

9 For a model that shows why hyperbolic discounters cannot reach their predetermined choice of savings and how (costly) commitment devices are useful for them, see John (2014).

10 Versions of this model exist throughout Latin America and the Caribbean. They have a variety of names: pandero or pandeiro in Peru and 
Brazil, juntas in the Dominican Republic, tandas in Mexico, and quiniela in several other countries.

11 For a review of the available commitment saving products in the region and their current challenges, see Martin (2014).

12 Multilateral Investment Fund's ProSavings program has financed the development of saving groups as well as individual scheduled savings accounts in the region, with a particular focus on beneficiaries of cash transfer programs and recipients of remittances from abroad.

13 Thaler and Benartzi's (2004) Save More Tomorrow ${ }^{\mathrm{TM}}$ does exactly this: not only are employees given the chance to commit themselves to save in advance, but permanence in the program is made the default option. The design takes into account the role of status quo bias. By doing so, the program has achieved high survival rates: 8 out of 10 participants are still saving even after four pay raises.

14 Mullainathan and Shafir (2014) highlight that poverty can also impact individuals' ability to process information, manage their time efficiently, or resist temptation, thus limiting their ability to make sound financial choices, forecast, or plan ahead.

15 This is not surprising, given that this is a selected sample of people who had already opted into the formal financial system.

16 The Innovation for Poverty Action (IPA) Messaging Project rigorously tests varying contents and methods of delivery of reminders that promote financial inclusion efforts.

17 The externalities that deter financial institutions from providing the first loan to a poor individual or group with no previous credit history are described in Lanuza (2004). Once the investment to extend a loan to a client is made, other providers in the market have incentives to poach the client and thus avoid the upfront costs paid by the first lender.

18 An example in India is the Prime Minister's People's Wealth Program, (Pradhan Mantri's Jan-Dhan Yojana), which planned to open 75 million accounts in a first phase that ended August 2015. In Chile, Cuenta RUT, a simplified saving account offered by Banco EstadoChile's National Bank, has positioned itself as the main means of payment and deposit accounts in the country. Many governments in Latin America and the Caribbean are also paying out conditional cash transfers through basic bank accounts, promoting the bancarization of the poorest segments of the population. Nevertheless, 
an ongoing debate rages over the unintended effects of social assistance programs on formal saving choices and trust in the formal financial system. In Argentina and Brazil, for example, the funds deposited into the formal account of beneficiary households are withdrawn whenever the household does not consume the total amount of the transfer during a given time frame. For a discussion on this topic, see Chapter 11. commons.org/licenses/by-nc-nd/3.0/igo/) and may be reproduced with attribution to the Inter-American Development Bank (IDB) and for any non-commercial purpose. No derivative work is allowed.

Any dispute related to the use of the works of the IDB that cannot be settled amicably shall be submitted to arbitration pursuant to the UNCITRAL rules. The use of the IDB's name for any purpose other than for attribution, and the use of IDB's logo shall be subject to a separate written license agreement between the IDB and the user and is not authorized as part of this CC-IGO license. Note that the link provided above includes additional terms and conditions of the license.

The images or other third party material in this chapter are included in the work's Creative Commons license, unless indicated otherwise in the credit line; if such material is not included in the work's Creative Commons license and the respective action is not permitted by statutory regulation, users will need to obtain permission from the license holder to duplicate, adapt or reproduce the material. 